\title{
Liposome-incorporated corticosteroids. II. Therapeutic activity in experimental arthritis
}

\author{
NIGEL C. PHILlips, D. PETER PAgE THOMAS, C. GRAHAM KNIGHT, \\ AND JOHN T. DINGLE
}

From the Tissue Physiology Department, Strangeways Research Laboratory, Cambridge.

SUMMARY The anti-inflammatory activity of liposomes containing cortisol palmitate was determined in experimental acute arthritis in the rabbit knee by measuring joint temperature and diameter. The therapeutic activity of the liposome preparation was dose-dependent for both these parameters of inflammation. Liposomal corticosteroid therapy was effective also in decreasing the joint temperature of an acute inflammatory 'flare' superimposed on an underlying chronic arthritis. Phosphatidic acid was necessary for expression of full anti-inflammatory activity of the liposome preparation.

Entrapment of a number of drugs in liposomes has led to an increase in their effectiveness and to a reduction in their toxicity (Fendler and Romero, 1977). We postulated that liposomal entrapment of the corticosteroid esters used for the management of acute episodes in rheumatoid arthritis (Hollander, 1972) would increase the efficacy of intra-articular steroid therapy (Shaw et al., 1976). In addition liposomes might be of value in reducing the side effects due to escape of steroid from the joint (Goetzl, et al. 1974).

Cortisol palmitate has been found to be efficiently incorporated and retained by dipalmitoyl phosphatidylcholine liposomes under physiological conditions (Shaw et al., 1976; Knight and Shaw, 1979). Preliminary investigations have shown that the intraarticular injection of liposomal cortisol palmitate was effective in reducing the temperature and swelling of an experimental acute arthritis in the rabbit knee joint (Dingle et al, 1978). Liposomal components were recovered from arthritic tissue after a single intraarticular injection and indicated that a substantial proportion of the liposomes were taken up by the synovium (Shaw et al., 1979).

In the present paper we report the response of an acute arthritis in rabbit knee joints to various doses of liposomal cortisol palmitate. We also report the effectiveness of liposomal corticosteroid therapy in the treatment of an acute inflammatory 'flare'. In addition some effects of modifying the liposome formulation on the anti-inflammatory activity have been studied.

Accepted for publication 19 December 1978

Correspondence to D. P. Page Thomas, Strangeways Research Laboratory, Worts's Causeway, Cambridge CB1 4RN.

\section{Materials and methods}

L- $\alpha$-dipalmitoyl phosphatidylcholine was obtained from Sigma (London) Chemical Co. Ltd., Poole, Dorset. Egg yolk phosphatidic acid (grade 1) was from Lipid Products, Redhill, Surrey. Poly-Dlysine hydrobromide (MW 175 000) and hyaluronic acid (human umbilical cord) were supplied by Miles Laboratories Ltd., Stoke Poges, Slough, Middlesex. 11- $\alpha$-Cortisol (epicortisol) was a gift from Glaxo Laboratories, Greenford, Middlesex. Cortisol 21-palmitate and epicortisol 21-palmitate were prepared by the methods described previously (Shaw et al., 1979). All other reagents were of analytical grade or equivalent. Sterile solutions were prepared by passage through a $0 \cdot 22 \mu \mathrm{m}$ membrane filter.

\section{LIPOSOME PREPARATION}

The standard liposome formulation was prepared under aseptic conditions as follows. Dipalmitoyl phosphatidylcholine $(6 \mathrm{mg})$, egg yolk phosphatidic acid $(1 \mathrm{mg})$, and cortisol palmitate $(3 \mathrm{mg})$ were dissolved in chloroform $(1.25 \mathrm{ml})$. This solution was rotary evaporated to dryness in vacuo at $55^{\circ} \mathrm{C}$, and the dried lipid film was hydrated at the same temperature by vortexing with $3 \mathrm{ml}$ sterile $5 \mathrm{mM}$ sodium phosphate buffered saline (PBS), pH 7.4. After $1 \mathrm{~h}$ at $21^{\circ} \mathrm{C}$ the liposome suspension was centrifuged at $50000 \mathrm{~g}$ for $10 \mathrm{~min}$, and the lipid pellet was resuspended in PBS $(2 \mathrm{ml})$. This procedure was repeated twice, and the cortisol concentration in the final suspension (approx. $0.45 \mathrm{mg} / \mathrm{ml}$ ) was determined by the fluorometric method of Zenker and Bernstein (1958). Other liposome formulations were made by the same procedures. 
EXPERIMENTAL ARTHRITIS

Male and female Old English rabbits $(1 \cdot 8-2 \cdot 4 \mathrm{Kg})$ were used. Before induction of the arthritis hair was removed from both knee joints by the use of a commercial depilatory cream. A bilateral arthritis was induced by the intra-articular injection of a preformed insoluble complex of poly-D-lysine and hyaluronic acid into both knee joints (Shaw et al., 1979).

An acute inflammatory flare, superimposed on an underlying chronic arthritis, was induced by giving a second injection of the polylysine-hyaluronate complex 28 days after the first injection.

\section{MEASUREMENT OF INFLAMMATION}

Radiometric measurement of joint temperature was carried out with a Heimann KT41 radiation thermometer (Phillips and Page Thomas, 1979). The radiation from an area of skin $0.6 \mathrm{~cm}$ in diameter situated on the anterolateral side of the knee over the joint space was measured. The diameter of the knee was measured in the coronal plane of the articular space with a calibrated spring-loaded Baty micrometer.

\section{TREATMENT OF EXPERIMENTAL ARTHRITIS}

Liposomes $(0.5 \mathrm{ml})$ containing the palmitate esters of cortisol, or epicortisol, were injected into one knee joint 4 days after the induction of the arthritis. The temperatures and diameters of injected and contralateral joints was monitored for 3-5 days after treatment. In the treatment of an acute inflammatory 'flare' superimposed on a chronic arthritis, liposomes were injected 4 days after induction of the acute episode.

\section{Results}

The effect of treatment of an experimental arthritis in rabbits with liposomes containing cortisol palmitate was investigated after the arthritis had developed for 4 days. It had previously been demonstrated that maximum anti-inflammatory activity was observed when liposomes were injected at this time; decreased activity was observed when treatment was started at 8 and 15 days after induction (Shaw et al., 1979).

\section{LIPOSOME DOSE-RESPONSE CURVES}

The effect of the intra-articular injection of various doses of liposomal cortisol palmitate on joint temperature is shown in Fig. 1. Maximum antiinflammatory activity was seen at a dose equivalent to 50-200 $\mu \mathrm{g}$ cortisol. In this dose range the joint temperature was reduced to the temperature range of normal rabbit joints $\left(31 \cdot 5 \pm 0 \cdot 5^{\circ} \mathrm{C}\right)$ for at least 3 days. The effect of liposomal therapy on joint diameter (Fig. 2) differed from that on joint temperature in that a plateau effect was not seen. Maxi- $\frac{}{\omega}$. mum reduction in temperature may not correlate therefore with maximum reduction in diameter. In $\stackrel{\vec{S}}{\rightarrow}$ subsequent experiments designed to study the effects of liposome formulation on anti-inflammatory activity liposomes contained the equivalent of $20 \mu \mathrm{g}$

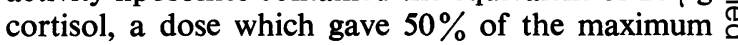
response for both parameters measured.

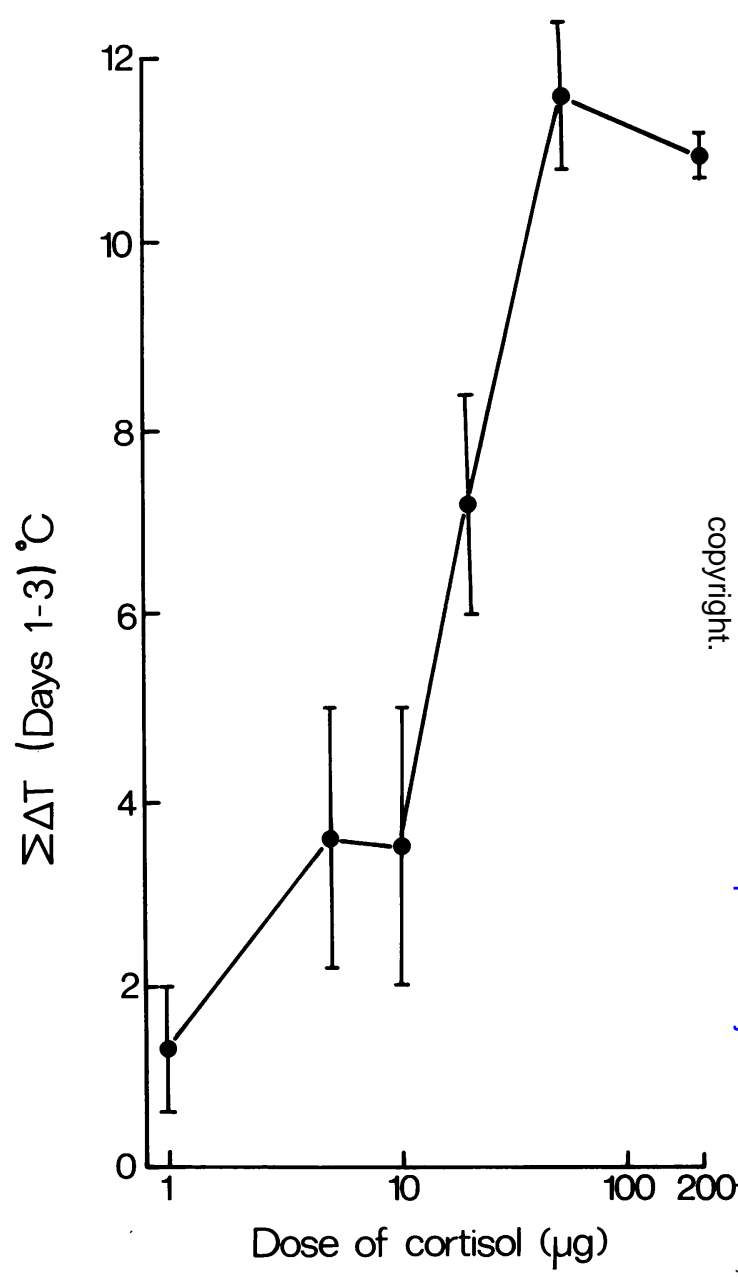

Fig. 1 The effect of liposomal cortisol palmitate on joint temperature. Four days after the induction of a bilateral experimental acute arthritis in rabbits one knee joint received an intra-articular injection of liposomes containing cortisol palmitate (equivalent to 1-200 $\mu \mathrm{g}$ cortisol). Joint temperature was measured as described in the 'Methods' section. Results are expressed as the sum of the differences from the pretreatment value on days 1-3 after treatment. Values are mean $( \pm S E M)$ of 4-6 determinations 


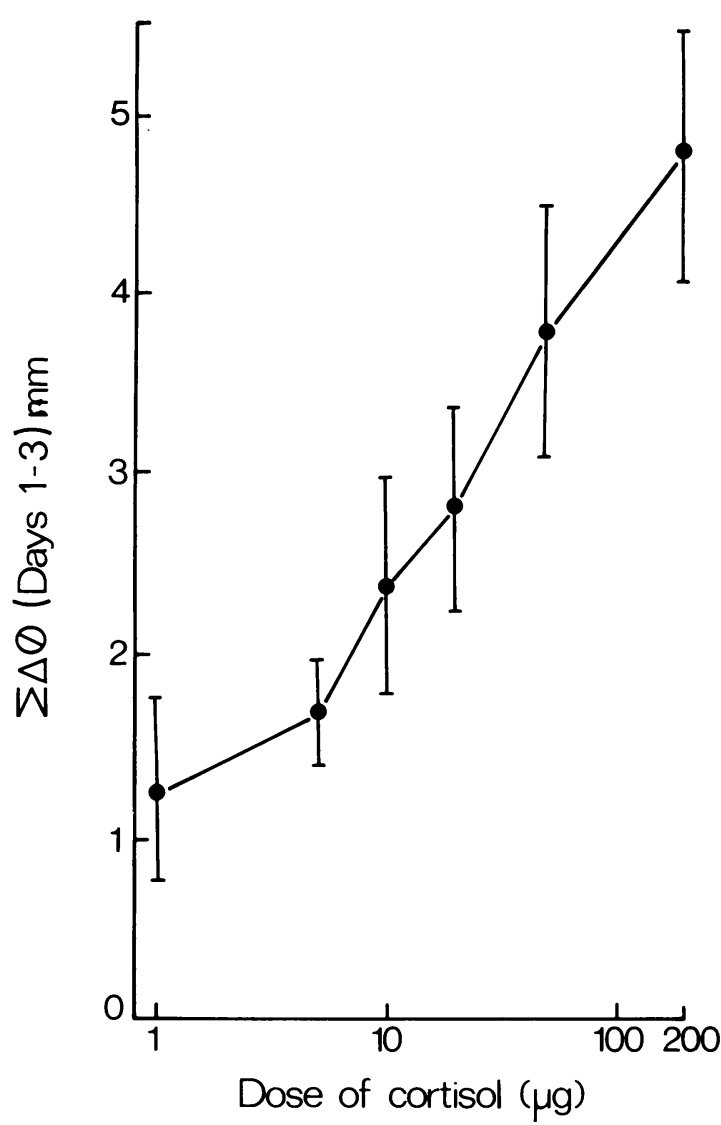

Fig. 2 The effect of liposomal cortisol palmitate on joint diameter. Experiments were carried out as described in the legend to Fig. 1. Joint diameter was measured as described in the 'Methods' section. Results are expressed as the sum of the differences from the pretreatment values on days 1-3 after treatment. Values are mean $( \pm S E M)$ of 4-6 determinations

\section{COMPARATIVE ANTI-INFLAMMATORY}

\section{ACTIVITY OF LIPOSOMAL CORTISOL}

PALMITATE AND EPICORTISOL PALMITATE

The effect of intra-articular therapy with liposomal cortisol palmitate was compared with that of liposomal epicortisol palmitate to determine the effect of a comparable control liposome preparation on joint temperature and diameter. Epicortisol has negligible glucocorticoid activity compared to cortisol (Simonsson, 1972). A direct comparison was made by injecting one preparation into the left knee and the other preparation into the right knee of a group of arthritic rabbits. The joints which received liposomal cortisol palmitate (equivalent to $20 \mu \mathrm{g}$ cortisol) showed a significant and sustained reduction in both joint temperature and diameter (Fig. 3). By contrast, no anti-inflammatory activity was observed in the contralateral knee, which received the same dose of liposomal epicortisol palmitate.
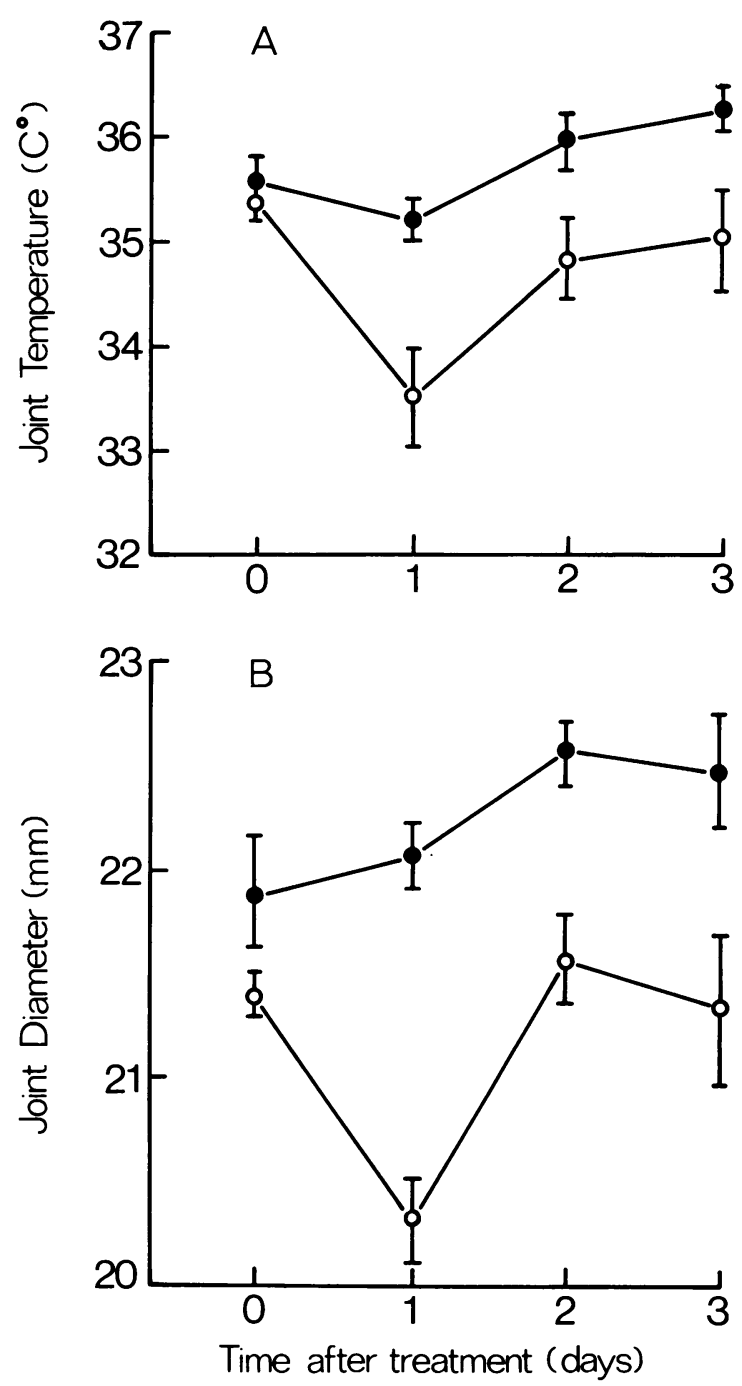

Fig. 3 Comparative anti-inflammatory activity of liposomal cortisol palmitate and epicortisol palmitate. Four days after the induction of a bilateral experimental acute arthritis in rabbits the left knee joint received an intra-articular injection of liposomal cortisol palmitate, equivalent to $20 \mu \mathrm{g}$ cortisol (0). The right knee joint received epicortisol palmitate, equivalent to $20 \mu \mathrm{g}$ epicortisol ( $\bullet$ ). A. Joint temperature. B. Joint diameter. Values are mean $( \pm S E M)$ of 6 determinations 


\section{LIPOSOMAL TREATMENT OF AN} EXPERIMENTAL FLARE

Liposomal cortisol palmitate was used to treat an induced acute inflammation superimposed on an underlying experimental chronic arthritis. As shown in Fig. 4, the intra-articular injection of liposomes 4 days after the induction of the acute episode resulted in a significant decrease in joint temperature to the pretreatment level. This temperature decrease was sustained for 2 days before returning to the level of the uninjected knee. Corresponding decreases in joint diameter were not observed.

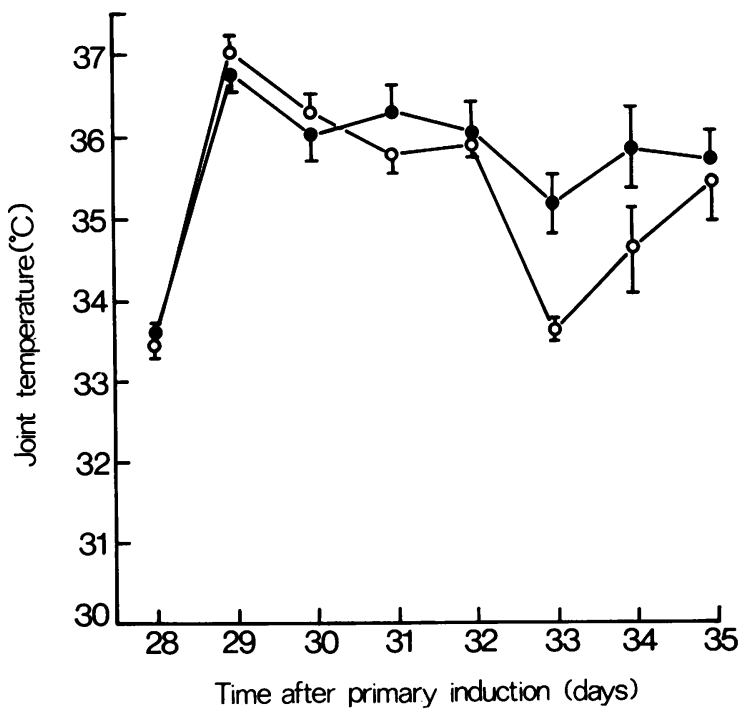

Fig. 4 Treatment of an experimentally induced 'flare' with liposomal cortisol palmitate. A bilateral acute episode was induced on an existing chronic inflammation at 28 days as described in the 'Methods' section. Liposomes containing cortisol palmitate (equivalent to $20 \mu \mathrm{g}$ cortisol) were injected into one knee 4 days after induction of the 'flare'. Treated knee, 0 ; Untreated knee, $\bullet$. Values are mean $( \pm S E M)$ of 6 determinations. The temperature of normal rabbit knee joints is 31.5 $( \pm 0 \cdot 5)^{\circ} \mathrm{C}$

\section{LIPOSOME FORMULATION AND ANTI-}

\section{INFLAMMATORY ACTIVITY}

The activities of other liposome preparations were calculated relative to the standard formulation, at a dose equivalent to $20 \mu \mathrm{g}$ cortisol. The experimental data were plotted as temperature or diameter change against days after treatment, and the areas defined by these lines and the baseline were compared. The standard formulation which reduced the inflammation for 3-4 days after treatment was given a relative activity of $1 \cdot 0$. Table 1 shows that when cortisol palmitate was replaced by epicortisol
Table 1 Liposome formulation and anti-inflammatory activity. Four days after the induction of a bilateral experimental arthritis in groups of 4-6 rabbits one knee joint of each animal received an intra-articular injection of liposomes $(0.5 \mathrm{ml})$ containing the equivalent of $20 \mu \mathrm{g}$ cortisol. The relative activities of the preparations were calculated as described in the text

\begin{tabular}{lllllll}
\hline \multicolumn{2}{l}{ Liposome formulation 12} & & $\begin{array}{c}\text { Anti- } \\
\text { inflam- }\end{array}$ & \multicolumn{2}{l}{ Relative activity } \\
\cline { 5 - 7 } DPPC & $P A$ & $C P$ & Epi-CP $\begin{array}{c}\text { matory } \\
\text { duration } \\
\text { in days }\end{array}$ & Temperature Diameter \\
\hline 6 & 1 & - & - & 0 & 0 & 0 \\
6 & 1 & 3 & - & $3-4$ & 1.0 & 1.0 \\
6 & 1 & - & 3 & 0 & 0.07 & 0.08 \\
6 & 1 & 0.6 & - & $1-2$ & 0.42 & 0.43 \\
7 & - & 1 & - & $1-2$ & 0.40 & 0.29 \\
\hline
\end{tabular}

1 Liposome formulation expressed as the weight $(\mathrm{mg})$ of components used to the preparative procedure. 2 Abbreviations are used: DPPC $=$ dipalmitoyl phosphatidylcholine; PA: phosphatidic acid; CP: cortisol of palmitate; Epi-CP: epicortisol palmitate.

palmitate there was an almost complete loss of antiinflammatory activity as measured by the reduction of joint temperature and diameter. Similarly, $\frac{\mathscr{T}}{3}$ liposomes formulated from dipalmitoyl phosphatidylcholine and phosphatidic acid alone had no measurable anti-inflammatory activity. We also observed some loss of anti-inflammatory activiti when the proportions of cortisol palmitate phosphatidic acid in the formulations were decrease

\section{Discussion}

Liposomal cortisol palmitate has been shown $\overrightarrow{\vec{A}}$ previously to be more effective in reducing the temperature and diameter of an experimental acute, rather than chronic, arthritis in the rabbit knee (Shaw et al., 1979). The present report has demonstrated that the anti-inflammatory activity of liposomal cortisol palmitate was dose-dependent for both parameters of inflammation. The increased activity observed at the higher dose levels arose from an increase in the duration, rather than the magnitude, of the anti-inflammatory effect.

No anti-inflammatory activity was observed with liposomal epicortisol palmitate and such liposome preparations had no proinflammatory properties when injected into normal rabbit knee joints (Dingle et al., 1978). We have therefore concluded that the vehicle used in these studies is devoid of $\mathrm{\omega}$ biological activity.

The treatment of an experimentally induced 0 'flare' by liposomal cortisol palmitate was investigated to assess the potential of such liposomal $\stackrel{\mathcal{C}}{\rightarrow}$ formulations for the treatment of a similar acute 0 articular episode in rheumatoid arthritis. A significant reduction in joint temperature but not joint 
diameter was observed. The probable explanation of the lack of correlation between the 2 parameters of inflammation in this instance is that exudation of fluid into the joint now constitutes only a minor component of the total swelling present, as much soft-tissue thickening and synovial proliferation have occurred by this time, and the measurement of diameter is unlikely to be sufficiently sensitive to reflect any changes which might occur. By contrast, in an acute synovitis exudation into the joint is the main reason for the increased joint diameter.

The anti-inflammatory activity of liposomal cortisol palmitate was influenced by the formulation of the liposome. In the absence of phosphatidic acid we observed decreases in both the magnitude and the duration of the therapeutic response. Decreasing the quantity of cortisol palmitate in the formulation had a similar effect. We have found that these changes in composition alter the physical state of the lipid bilayers. Liposomes made with the standard formulation are in a fluid state at $36^{\circ} \mathrm{C}$, the temperature of the inflamed rabbit knee. When phosphatidic acid was omitted the lipid bilayers became largely solid at the same temperature (C. G. Knight, D. P. Page Thomas, and J. J. Cowper, unpublished observations). It would appear therefore that the physical state of the lipid bilayers is of some importance in determining the anti-inflammatory activity.

We thank ICI Pharmaceutical Division (N.C.P.) and the Arthritis and Rheumatism Council (C.G.K.) for financial support. D.P.P.T. and J.T.D. are members of the MRC external staff. This work forms part of a collaborative study between Strangeways Research Laboratory and ICI Ltd., Pharmaceuticals Division.

\section{References}

Dingle, J. T., Gordon, J. L., Hazleman, B. L., Knight, C. G., Page Thomas, D. P., Phillips, N. C., Shaw, I. H., Fildes, F. J. T., Oliver, J. E., Turner, E. H., and Lowe, J. S. (1978). Novel treatment for joint inflammation. Nature, 271, 372-373.

Fendler, J. H., and Romero, A. (1977). Liposomes as drug carriers. Life Sciences, 20, 1109-1120.

Goetzl, E. J., Bianco, N. E., Alpert, J. S., Sledge, C. B., and Schur, P. H. (1974). Effect of intra-articular corticosteroids in vivo on synovial fluid variables in rheumatoid synovitis. Annals of the Rheumatic Diseases, 33, 62-66.

Hollander, J. L. (1972). Intrasynovial corticosteroid therapy. In Arthritis and Allied Conditions, pp. 517-534. Edited by J. L. Hollander and D. J. MacCarty. Lea and Febiger: Philadelphia.

Knight, C. G., and Shaw, I. H. (1979). Liposomes as carriers of anti-inflammatory steroids. In Lysosomes in Biology and Pathology, Vol. 6 (in press). Edited by J. T. Dingle and P. J. Jacques. Elsevier/North Holland Biomedical Press BV: Amsterdam.

Phillips, N. C., and Page Thomas, D. P. (1979). Monitoring of experimental arthritis in rabbits. Annals of the Rheumatic Diseases, 38, 89-93.

Shaw, I. H., Knight, C. G., and Dingle, J. T. (1976). Liposomal retention of a modified anti-inflammatory steriod. Biochemical Journal, 158, 473-476.

Shaw, I. H., Knight, C. G., Page Thomas, D. P., Phillips, N. C., and Dingle, J. T. (1979). Liposome-incorporated corticosteroids. I. The interaction of liposomal cortisol palmitate with inflammatory synovial membrane. British Journal of Experimental Pathology, 60, 142-150.

Simonsson, B. (1972). Uptake of ${ }^{3} \mathrm{H}$-cortisol by rabbit polymorphonuclear leukocytes in vitro. III. Structural evidence for a specific glucocorticoid uptake. Steroids, 20, 23-39.

Zenker, N., and Bernstein, D. E. (1958). The estimation of small amounts of corticosterone in rat plasma. Journal of Biological Chemistry, 231, 695-701. 